\title{
40. ROCK MAGNETISM OF IGNEOUS ROCKS FROM DEEP SEA DRILLING PROJECT SITES 482, 483, AND 485 $^{1}$
}

\author{
Ron Day and Mary Osterhoudt, University of California, Santa Barbara, California \\ and \\ Ulrich Bleil, Institut für Geophysik, Ruhr-Universität, Bochum, Postfach 1021 48, West Germany
}

During DSDP Leg 65, we achieved significant basement penetration at three sites $(482,483$, and 485$)$ in the mouth of the Gulf of California (Lewis and Robinson, this volume). Since these holes were all drilled into extremely young crust near the crest of the East Pacific Rise, the rocks we recovered present an unusual opportunity to study the magnetic properties of submarine basalts before alteration has become pervasive. To take advantage of this opportunity and to complement the paleomagnetic studies conducted on these basalts by Day (this volume), we have studied, in the same samples, the following properties: saturation magnetization $\left(J_{S}\right)$; intensity and stability of isothermal remanent magnetization (IRM); hysteresis parameters, such as the coercive force $\left(H_{C}\right)$, the remanent coercive force $\left(H_{R C}\right)$, and the ratio of saturation remanence $\left(J_{R S}\right)$ to saturation magnetization; susceptibility $(\chi)$; and Curie temperature $\left(T_{c}\right)$. In this chapter we will discuss the results of these studies in conjunction with the opaque mineralogy of the samples.

\section{METHOD}

With the exception of thermomagnetic analysis and microscope observations, we conducted studies of the samples' magnetic properties at the Rock Magnetism Laboratory, University of California, Santa Barbara.

We took the remanent magnetization measurements before and after AF demagnetization on a Schönstedt spinner magnetometer. Samples were progressively demagnetized to at least $10 \%$ of their initial intensity with a Schönstedt single-axis demagnetizer. We studied the acquisition of isothermal remanent magnetization in selected samples from each hole before these were given in a saturation isothermal remanent magnetization. Hysteresis loops were obtained using a vibrating sample magnetometer similar to that described by Kobayashi and Fuller (1967). From each loop we read saturation magnetization, coercive force, and the ratio of saturation remanence to saturation magnetization. The remanent coercive force was obtained from the direct field demagnetization of the saturation remanence. Susceptibility was measured both aboard ship (Day, this volume) and on an AC susceptibility bridge. All of the instruments can accommodate standard paleomagnetic cores $(2.54 \mathrm{~cm}$ diameter $\times 2.54 \mathrm{~cm}$ length).

Thermomagnetic curves were measured at the Institut für Geophysik, Ruhr-Universität, Bochum, using an automatic recording magnetic-translation balance with an applied field of $2.5 \mathrm{kOe}$. All measurements were made in argon to a maximum temperature of about $625^{\circ} \mathrm{C}$ at heating and with a cooling rate of $40^{\circ} \mathrm{C} / \mathrm{min}$. The extremely low oxygen fugacity atmosphere effectively prevents oxidation of the magnetic oxides. As illustrated in Figure 1A, Curie temperatures were determined using a simple graphic technique (Grommé

'Lewis, B. T. R., Robinson, P., et al., Init. Repts. DSDP, 65: Washington (U.S. Govt. Printing Office). et al., 1963). As an aid to interpreting the thermomagnetic data, we examined polished sections of selected samples under reflected light using a Leitz Ortholux Pol microscope.

\section{RESULTS}

The magnetic properties we studied are listed in Table 1 in order of increasing depth in each hole for all of the samples studied. Also shown in Table 1 are the Curie temperatures of the samples in polished section and the values of natural remanent magnetization $\left(J_{N R M}\right)$, stable inclination $\left(I_{0}\right)$, and the Koenigsberger ratio $(Q)$, presented by Day (this volume) for the same samples.

\section{Thermomagnetic Analysis}

We selected 37 samples for thermomagnetic analysis. The Curie temperatures found during heating and cooling are listed in Table 1, and Figure 1 shows typical thermomagnetic curves. As has been found in most other studies of oceanic basalts, the thermomagnetic curves reflect both reversible and irreversible behavior and a wide range of Curie temperatures. With few exceptions only one Curie temperature is observed per sample, indicating the presence of what is essentially a single phase magnetic mineral. None of the samples exhibited a truly reversible curve, but as in previous studies, a curve is considered reversible if the Curie temperature between the heating and cooling limbs differs by less than $50^{\circ} \mathrm{C}$ and if only minor changes $(<20 \%)$ in magnetization occur between the initial and final room-temperature magnetization. Figure 1A, for example, shows a reversible thermomagnetic curve.

Though most commonly associated with samples in which the Curie temperature is low $\left(<250^{\circ} \mathrm{C}\right)$, reversible curves are also associated with samples that have intermediate or high Curie temperatures (e.g., Sections $482 \mathrm{C}-11-1,97 \mathrm{~cm}$ and $482 \mathrm{D}-8-1,106 \mathrm{~cm}$, respectively), and an approximately reversible curve was obtained for one of the samples (Section 482B-16-1, $117 \mathrm{~cm}$ ) that displayed two Curie temperatures (Fig. 1C).

In contrast, about $30 \%$ of the thermomagnetic curves are clearly irreversible, and the Curie temperatures determined from the heating and cooling limbs differ by up to $277^{\circ} \mathrm{C}$. Figures $1 \mathrm{~B}$ and $1 \mathrm{D}$ are typical examples of this behavior. Without exception, samples whose curves were irreversible exhibited a lower Curie temperature and a decrease in magnetization upon cooling. This behavior is not typical of oceanic basalts; in most studies, the irreversible thermomagnetic curves are characterized by an initial Curie temperature between $200^{\circ} \mathrm{C}$ and 
Table 1. Magnetic properties and Curie temperatures of basalts from Sites 482,483 , and 485 .

\begin{tabular}{|c|c|}
\hline $\begin{array}{c}\text { Sample } \\
\text { (level in cm) }\end{array}$ & $\begin{array}{l}\text { Vol. } \\
\left(\mathrm{cm}^{3}\right)\end{array}$ \\
\hline Hole 482B & \\
\hline $\mid 1-1,21$ & 12.16 \\
\hline $11.2,41$ & 11.91 \\
\hline $11-3,15$ & 11.91 \\
\hline $12-1,63$ & 11.91 \\
\hline $12-2,143$ & 11.91 \\
\hline $13-1,126$ & 11.91 \\
\hline $14-1,97$ & 11.40 \\
\hline $14-3,126$ & 11.91 \\
\hline $15-1,16$ & 11.91 \\
\hline $15-2,39$ & 11.91 \\
\hline $15-3,114$ & 11.91 \\
\hline $15-4,125$ & 11.91 \\
\hline $16-1,31$ & 12.16 \\
\hline $16-1,84$ & 11.65 \\
\hline $16-1,100$ & 11.91 \\
\hline $16-1,117$ & 12.16 \\
\hline $16-2,87$ & 11.91 \\
\hline $16 \cdot 3,78$ & 11.91 \\
\hline $16-4,42$ & 11.91 \\
\hline $16-4,125$ & 11.91 \\
\hline $17-1,70$ & 12.16 \\
\hline $17-2,55$ & 11.65 \\
\hline $18-1,16$ & 11.65 \\
\hline $18-2,84$ & 11.91 \\
\hline $19-1.78$ & 12.16 \\
\hline $19 \cdot 1,108$ & 11.65 \\
\hline $19-1,134$ & 10.64 \\
\hline $20-1,39$ & 11.91 \\
\hline $20-1,143$ & 11.91 \\
\hline $20-3,17$ & 11.65 \\
\hline $20-3,141$ & 11.65 \\
\hline $21-1,95$ & 11.15 \\
\hline $21-2,33$ & 11.91 \\
\hline $21-2,78$ & 12.06 \\
\hline $21-2,111$ & 11.91 \\
\hline $21-3,69$ & 11.91 \\
\hline $22-1,83$ & 11.65 \\
\hline $22-2,32$ & 11.91 \\
\hline $22-3,99$ & 12.16 \\
\hline $22-4,57$ & 11.40 \\
\hline $24-1,43$ & 11.91 \\
\hline $24-2,106$ & 11.40 \\
\hline $24-3,70$ & 11.40 \\
\hline Hole $482 \mathrm{C}$ & \\
\hline $9-1,113$ & 11.91 \\
\hline $9-1,138$ & 11.50 \\
\hline $10-2,58$ & 11.65 \\
\hline $10-2,61$ & 11.91 \\
\hline $10-2,78$ & 11.91 \\
\hline $10-3,119$ & 11.65 \\
\hline $11-1,97$ & 11.40 \\
\hline $11-2,11$ & 11.65 \\
\hline $11-2,44$ & 11.40 \\
\hline $11-3,26$ & 11.65 \\
\hline $11-3,63$ & 11.65 \\
\hline $11-3,128$ & 11.76 \\
\hline $11-4,107$ & 11.40 \\
\hline $12-1,39$ & 11.76 \\
\hline $12-1,146$ & 11.76 \\
\hline $12-2,92$ & 11.30 \\
\hline $13-1,56$ & 11.65 \\
\hline $13-2,17$ & 11.65 \\
\hline $13-2,96$ & 12.16 \\
\hline $13-3,25$ & 11.40 \\
\hline $13-3,80$ & 11.50 \\
\hline $13-3,132$ & 11.15 \\
\hline $14-1,44$ & 11.50 \\
\hline $14-2,22$ & 11,81 \\
\hline $14-2,131$ & 11.76 \\
\hline $14-3,77$ & 11.65 \\
\hline $14-3,122$ & 11.40 \\
\hline $14-4,61$ & 11.65 \\
\hline $14-4,132$ & 11.40 \\
\hline $14-5,46$ & 11.40 \\
\hline $15-1,42$ & 11.91 \\
\hline $15-2,11$ & 11.76 \\
\hline $15-2,92$ & 11.65 \\
\hline $15-4,68$ & 11.91 \\
\hline $15-4,117$ & 11.15 \\
\hline Hole 482 D & \\
\hline $8-1,10$ & 11.15 \\
\hline $9-1,51$ & 11.40 \\
\hline $9-2,106$ & 11.15 \\
\hline $9-3,23$ & 11.65 \\
\hline $9-3,54$ & 11.65 \\
\hline $10-1,69$ & 10.89 \\
\hline $10-2,11$ & 11.15 \\
\hline $10-2,57$ & 10.89 \\
\hline $10-2,111$ & 11.65 \\
\hline $10-3,18$ & 11.40 \\
\hline $10-3,109$ & 11.40 \\
\hline $11-1,128$ & 10.64 \\
\hline $11-3,80$ & 11.40 \\
\hline $12-1,27$ & 11.65 \\
\hline $12-1,65$ & 11.65 \\
\hline
\end{tabular}


Table 1. (Continued).

\begin{tabular}{|c|c|c|c|}
\hline $\begin{array}{c}\text { Sample } \\
\text { (level in } \mathrm{cm} \text { ) }\end{array}$ & $\begin{array}{l}\text { Vol. } \\
\left(\mathrm{cm}^{3}\right)\end{array}$ & $\begin{array}{l}\text { Depth } \\
\text { (m) }\end{array}$ & $\begin{array}{c}J \text { NRM } \\
\left(\times 10^{-3} \text { gauss }\right)\end{array}$ \\
\hline Hole $482 \mathrm{D}$ (C & ont.) & & \\
\hline $12-1,119$ & 11.65 & 169.69 & 6.00 \\
\hline $12-2,86$ & 11.65 & 170.86 & 20.4 \\
\hline $12-3,21$ & 11.65 & 171.71 & 10.2 \\
\hline$|2-3,6|$ & 11.65 & 172.11 & 11.5 \\
\hline $12 \cdot 3,122$ & 11.27 & 172.72 & 3.25 \\
\hline $12-4.45$ & 11.00 & 173.45 & 17.99 \\
\hline $13-1,127$ & 10.89 & 178.77 & 6.99 \\
\hline $13-2,12$ & 11.15 & 179.12 & 9.66 \\
\hline $13-3,33$ & 9.63 & 186.83 & 2.41 \\
\hline Hole $482 \mathrm{~F}$ & & & \\
\hline $4 \cdot 3,129$ & 11.65 & 136.79 & 9.30 \\
\hline $5 \cdot 1,7$ & 11.40 & 142.07 & 9.79 \\
\hline $5-1,141$ & 11.40 & 143.41 & 11.35 \\
\hline Hole 483 & & & \\
\hline $13-4,13$ & 1130 & 110.13 & \\
\hline $\begin{array}{l}13-4,13 \\
13-4,89\end{array}$ & $\begin{array}{l}11.30 \\
10.64\end{array}$ & $\begin{array}{l}110.13 \\
110.89\end{array}$ & $\begin{array}{l}6.63 \\
5.91\end{array}$ \\
\hline $\begin{array}{l}13-4,89 \\
14-1,31\end{array}$ & $\begin{array}{l}10.64 \\
11.65\end{array}$ & $\begin{array}{l}110.89 \\
115.31\end{array}$ & $\begin{array}{l}5.91 \\
5.33\end{array}$ \\
\hline $14-1,83$ & 9.98 & 115.83 & \\
\hline $\begin{array}{l}14-1,83 \\
14-2,10\end{array}$ & 11.45 & $\begin{array}{l}115.83 \\
116.60\end{array}$ & $\begin{array}{l}4.28 \\
5.25\end{array}$ \\
\hline $14-2,53$ & 10.39 & 117.03 & \\
\hline $14-2,106$ & 11.25 & 117.56 & $\begin{array}{l}2.47 \\
3.92\end{array}$ \\
\hline $15-1,20$ & 11.40 & 124.20 & $\begin{array}{l}3.92 \\
3.03\end{array}$ \\
\hline $15-1,102$ & 10.39 & 125.02 & $\begin{array}{l}3.03 \\
2.23\end{array}$ \\
\hline $15-2,99$ & 11.40 & 126.49 & 3.01 \\
\hline $15 \cdot 3,4$ & 11.50 & 127.04 & 3.42 \\
\hline $16-1,54$ & 11.25 & 133.54 & 3.62 \\
\hline $16-1,112$ & 11.25 & 134.12 & 1.21 \\
\hline $16-1,138$ & 11.65 & 134.38 & 2.38 \\
\hline $16-2,14$ & 11.35 & 134.64 & 2.53 \\
\hline $16-2,62$ & 11.40 & 135.12 & 3.98 \\
\hline $16-2,140$ & 11.65 & 135.90 & 1.85 \\
\hline $17-1,60$ & 11.55 & 142.60 & 1.59 \\
\hline $17-2,30$ & 10.24 & 143.80 & 1.46 \\
\hline $17-2,96$ & 10.13 & 144.46 & 2.71 \\
\hline $17-3,20$ & 9.98 & 145.20 & 1.85 \\
\hline $18-4,110$ & 11.65 & 156.60 & 2.03 \\
\hline $18-4,148$ & 11.15 & 157.08 & 2,72 \\
\hline $20-1,14$ & 10.29 & 169.14 & 18.9 \\
\hline $20-1,110$ & 12.16 & 170.10 & 19.4 \\
\hline $20-1,142$ & 11.40 & 170.42 & 18.8 \\
\hline $20-2,22$ & 10.13 & 170.72 & 12.4 \\
\hline $20-3,29$ & 10.64 & 178.29 & 21.1 \\
\hline $21-1,106$ & 11.40 & 179.06 & 7.32 \\
\hline $21-2,4$ & 11.15 & 179.54 & 17.3 \\
\hline $21-2,39$ & 11.00 & 179.89 & 18.7 \\
\hline $21-2,124$ & 10.89 & 180.84 & 12.3 \\
\hline $22-1,84$ & 11.40 & 183.34 & 24.4 \\
\hline $22-1,135$ & 9.98 & 183.85 & 28.5 \\
\hline $22-2,77$ & 7.88 & 184.77 & 25.8 \\
\hline $22-3,103$ & 10.13 & 186.53 & 22.5 \\
\hline $22-4,35$ & 11.40 & 187.35 & 24.5 \\
\hline $22-4,103$ & 11.25 & 188.02 & 8.43 \\
\hline $23-1,64$ & 11.65 & 187.64 & 25.5 \\
\hline $23-1,113$ & 9.88 & 188.13 & 14.1 \\
\hline $23-2,37$ & 11.65 & 188.87 & 10.3 \\
\hline $23-2,120$ & 9.83 & 189.70 & 19.9 \\
\hline $24-1,48$ & 11.25 & 191.98 & 7.52 \\
\hline $24-2,4$ & 11.30 & 193.04 & 13.9 \\
\hline $24-2,61$ & 11.55 & 193.61 & 6.95 \\
\hline $25-1,24$ & 11.20 & 196.24 & 31.2 \\
\hline $25-1,84$ & 12.16 & 196.84 & 14.9 \\
\hline $25-2,74$ & 11.65 & 198.24 & 5.89 \\
\hline $26-1,11$ & 12.06 & 200.11 & 7.88 \\
\hline $26-1,138$ & 12.26 & 201.38 & 5.22 \\
\hline $26 \cdot 2,13$ & 10.44 & 201.63 & 6.55 \\
\hline $26-2,60$ & 10.39 & 202.10 & 28.5 \\
\hline $26-3,8$ & 12.16 & 203.80 & 16.2 \\
\hline $26-3,118$ & 10.64 & 204.18 & 6.34 \\
\hline Hole 483B & & & \\
\hline $2-7,91$ & 10.74 & 110.91 & 8.14 \\
\hline $3-1,46$ & 10.69 & 110.96 & 7.28 \\
\hline $3-1,121$ & 10.13 & 111.71 & 6.05 \\
\hline $4-1,64$ & 9.93 & 120.14 & 2.27 \\
\hline $4-2,83$ & 11.15 & 121.83 & 2.13 \\
\hline $4-3,127$ & 10.94 & 123.77 & 2.38 \\
\hline $4-4,111$ & 11.15 & 125.11 & 1.31 \\
\hline $4-5,94$ & 11.05 & 126.44 & 2.03 \\
\hline $4-7,4$ & 11.25 & 128.54 & 2.64 \\
\hline Hole $485 \mathrm{~A}$ & & & \\
\hline $11-3,79$ & 11.15 & 149.29 & 2.90 \\
\hline $12-1,59$ & 11.18 & 155.59 & 12.47 \\
\hline $13-1,96$ & 11.40 & 158.96 & 6.42 \\
\hline $14-1,60$ & 11.65 & 160.10 & 7.48 \\
\hline $17-1,108$ & 11.15 & 182.30 & 10.06 \\
\hline $17.2,77$ & 10.89 & 183.77 & 9.16 \\
\hline $18-2,29$ & 11.15 & 183.79 & 7.21 \\
\hline $23-1,99$ & 11.15 & 212.49 & 8.07 \\
\hline $23-4,12$ & 10.89 & 216.12 & 6.60 \\
\hline $24-2,21$ & 11.40 & 217.71 & 5.08 \\
\hline $25-2,29$ & 10.89 & 222.79 & 6.92 \\
\hline $25-3,29$ & 10.89 & 225.29 & 7.15 \\
\hline $29-1,20$ & 11.40 & 239.70 & 1.87 \\
\hline $29-2,123$ & 11.15 & 242.23 & 3.78 \\
\hline
\end{tabular}


Table 1. (Continued).

\begin{tabular}{|c|c|c|c|c|c|c|c|c|c|c|c|c|c|c|c|c|}
\hline $\begin{array}{c}\begin{array}{c}\text { Sample } \\
\text { (level in } \mathrm{cm} \text { ) }\end{array} \\
\end{array}$ & $\begin{array}{c}\text { Vol, } \\
\left(\mathrm{cm}^{3}\right)\end{array}$ & $\begin{array}{c}\text { Depth } \\
\text { (m) }\end{array}$ & $\begin{array}{c}J_{\text {NRM }} \\
(\times 10-3 \text { gauss }) \\
\end{array}$ & $\begin{array}{l}I \\
\left({ }^{\circ}\right)\end{array}$ & $\begin{array}{c}\operatorname{MDF}(1) \\
(O e)\end{array}$ & $\underset{\text { (gauss) }}{J_{R S}}$ & $\begin{array}{c}\operatorname{MDF}(2) \\
(\mathrm{Oe})\end{array}$ & $\underset{\text { (gauss) }}{J_{S}}$ & $J_{R S} / J_{S}$ & $\begin{array}{l}\mathrm{HC}_{\mathrm{C}} \\
(\mathrm{Oe})\end{array}$ & $\begin{array}{l}H_{R C} \\
\text { (Oe) }\end{array}$ & $H_{R C} H_{C}$ & $\left(\times 10^{-x^{-}}\right.$gauss $)$ & $Q$ & $\begin{array}{c}T_{C} \text { (heating) } \\
\left({ }^{\circ} \mathrm{C}\right)\end{array}$ & $\begin{array}{c}T_{C} \text { (cooling) } \\
\left({ }^{\circ} \mathrm{C}\right)\end{array}$ \\
\hline \multicolumn{17}{|c|}{ Hole 485A (Cont.) } \\
\hline $29-4,48$ & 11.15 & 244.48 & 7.03 & 30 & 117 & 0.385 & 40 & 3.50 & 0.11 & 45 & 105 & 2.33 & 3.68 & 4.25 & & \\
\hline $30-1,43$ & 11.15 & 249.93 & 9.34 & 24 & 155 & 0.474 & 70 & 2.49 & 0.19 & 62 & 127 & 2.05 & 3.26 & 6.36 & $269+512$ & 217 \\
\hline $30-3,105$ & 11.40 & 253.55 & -5.60 & 19 & 75 & 0.281 & 36 & 3.12 & 0.09 & 38 & 83 & 2.18 & 2.98 & 4.17 & & \\
\hline $31-2,85$ & 11.15 & 256.85 & 5.77 & 20 & 115 & 0.415 & 62 & 3.46 & 0.12 & 60 & 110 & 1.83 & 2.89 & 4.44 & & \\
\hline $32-1,10$ & 10.89 & 259.10 & 5.30 & 25 & 140 & 0.286 & 75 & 2.60 & 0.11 & 53 & 138 & 2.60 & 2.41 & 4.90 & $293+482$ & 262 \\
\hline $32-3,58$ & 10.89 & 262.55 & 2.25 & 22 & $123 ?$ & 0.247 & 50 & 2.06 & 0.12 & 27 & 107 & 3.96 & 3.09 & 1.62 & & \\
\hline $32-5,138$ & 11.40 & 266.38 & 3.18 & 22 & 130 & 0.264 & 56 & 3.30 & 0.08 & 45 & 118 & 2.62 & 3.07 & 2.30 & & \\
\hline $32-6,69$ & 11.15 & 267.19 & 2.37 & 22 & 148 & 0.239 & 50 & 2.99 & 0.08 & 38 & 110 & 2.89 & 3.01 & 1.75 & & \\
\hline $33-2,81$ & 11.15 & 270.31 & 2.64 & 25 & 110 & 0.306 & 75 & 3.40 & 0.09 & 62 & 170 & 2.74 & 2.55 & 1.99 & & \\
\hline $34-2,68$ & 11.15 & 274.18 & 6.79 & $39 ?$ & 34 & 0.268 & 22 & 2.98 & 0.09 & 27 & 47 & 1.74 & 3.49 & 4.33 & 182 & 122 \\
\hline $35-1,26$ & 11.15 & 286.26 & 6.40 & 38 & 45 & 0.260 & 25 & 2.60 & 0.10 & 24 & 53 & 2.21 & 3.98 & & & \\
\hline $35-3,72$ & 11.40 & 289.72 & 6.29 & 38 & 55 & 0.281 & 25 & 2.81 & 0.10 & 28 & 59 & 2.10 & 3.77 & 3.7 & & \\
\hline $35-4,47$ & 11.15 & 290.97 & 5.38 & 39 & 45 & 0.256 & 23 & 2.33 & 0.11 & 27 & 57 & 2.11 & 3.38 & 3.53 & & \\
\hline $35-6,44$ & 11.15 & 293.94 & 5.68 & 38 & 40 & 0.283 & 23 & 2.18 & 0.13 & 25 & 53 & 2.12 & 3.21 & & & \\
\hline $38-2,67$ & 11.40 & 315.17 & 0.83 & -55 & 135 & 0.472 & 65 & 2.78 & 0.17 & 79 & 115 & 1.46 & 2.20 & 0.84 & & \\
\hline $38-4,102$ & 11.15 & 318.52 & 1.16 & -43 & 22 & 0.284 & 42 & 2.58 & 0.11 & 37 & 88 & 2.38 & 2.86 & 0.90 & & \\
\hline $38-6,35$ & 11.65 & 320.85 & 2.31 & 64 & 35 & 0.307 & 30 & 3.07 & 0.10 & 32 & 64 & 2.0 & 3.22 & 1.60 & 253 & 158 \\
\hline $39-2,77$ & 11.15 & 324.27 & 2.78 & $?$ & 28 & 0.410 & 23 & 3.15 & 0.13 & 32 & 57 & 1.78 & 3.13 & 1.97 & & \\
\hline $39-4,27$ & 11.40 & 326.72 & 2.98 & ? & 40 & 0.393 & 27 & 3.02 & 0.13 & 30 & 60 & 2.0 & & & & \\
\hline $39-5,8$ & 11.40 & 328.80 & 1.14 & $?$ & 20 & 0.340 & 33 & 2.83 & 0.12 & 39 & 66 & 1.69 & 2.71 & 0.93 & 273 & 197 \\
\hline
\end{tabular}

Note: $J_{\mathrm{NRM}}=$ natural remanent magnetization; $I_{0}=$ stable inclination; $\mathrm{MDF}(1)=$ mean destruction field from isothermal remanence demagnetization; $J_{S}=$ saturation magnetization; $H_{C}=$ coercive force; $H_{R C}=$ remanent coercive force; $x=$ susceptibility; $Q=$ Koenigsberger ratio based on a magnetic field $H_{0}=0.45$ Oe; $T_{C}$ (heating) $=$ Curie temperature from heating curve; $T_{c}$ (cooling) $=$ Curie temperature from cooling curve.

$400^{\circ} \mathrm{C}$ during heating, followed by an increase in magnetization between $400^{\circ} \mathrm{C}$ and $500^{\circ} \mathrm{C}$, which falls off to zero at about $550^{\circ} \mathrm{C}$. After cooling, furthermore, the magnetization usually increases by a factor of two or more. These features were not observed in any of our samples.

We performed a number of tests to exclude the possibility that this effect was due to our measuring technique. For the heating rate $\left(40^{\circ} \mathrm{C} / \mathrm{min}\right.$.), only a small contribution $\left(<20^{\circ} \mathrm{C}\right)$ could be attributed to instrument error, and the data in Table 1 and in the figures have been corrected accordingly. It should also be noted that similar thermomagnetic properties have been reported for Leg 65 basalts by Pechersky et al. (this volume).

\section{Microscope Observations}

We made polished sections from the same samples that were used for thermomagnetic analysis. In all samples, the predominant opaque mineral is titanomagnetite, the volume content of which varies from about $0.5 \%$ in the pillow basalts to about $5 \%$ in the flow units. The grain size of the opaques in the pillow basalts ranges from below the limit of optical resolution to about 10 $\mu \mathrm{m}$, and the grains are typically anhedral. Coarsergrained opaques occur in the flow units where grain size averages several tens of microns and occasionally reaches several hundred microns. Skeletal-to-subhedral forms are most abundant, and inclusions could be seen in many of the larger grains. Some samples from the flow units had a second, finer-grained titanomagnetite fraction $(10 \mu \mathrm{m}$ or less) in the matrix. Most of the titanomagnetite grains appeared to be homogeneous and features associated with low temperature oxidation, such as curved and branching cracks, are clearly developed only in a few samples showing a high Curie temperature.

In some samples, ilmenite occurs as separate primary laths. Ilmenite is also present as a secondary mineral in Sections 482D-8-1, $106 \mathrm{~cm}$ and 482B-16-1, $117 \mathrm{~cm}$. It is not a result of high temperature deuteric oxidation in this instance, since there are no systematic lamellae present. Instead, there is an irregular intergrowth within the host titanomagnetite, indicating that it was produced by decomposition of titanomaghemite (perhaps because of hydrothermal activity).

\section{Saturation Magnetization $\left(J_{S}\right)$ and Saturation Isothermal Remanence $\left(J_{R S}\right)$}

The variation in saturation magnetization both within and between holes is very small. This can be seen in the average values given in Table 2 as well as in the individual measurements listed in Table 1 . The saturation magnetization averages 2.0 gauss, a value close to the mean value found for unoxidized samples from Leg 49 (Day et al., 1979). There is a greater variation in the saturation isothermal remanence values; but this is to be expected since $J_{R S}$ is dependent on grain size and shape as well as on composition and concentration, whereas $J_{S}$ is independent of grain size, although it is related to grain size by oxidation, when oxidation has taken place. The distribution of $J_{R S} / J_{S}$ values is shown in Figure 2. The majority of the samples have values of 0.1 to 0.2 , indicating pseudo single domain grains. There is only one peak in the Leg 65 histogram whereas the Leg 49 histogram was bimodal. Again, it is apparent that only relatively fresh titanomagnetites are found in the Leg 65 basalts. Many of the high $J_{R S} / J_{S}$ values are associated with pillow basalts, as would be expected since they contain much finer titanomagnetite grains.

\section{Coercive Force $\left(H_{C}\right)$, Remanent Coercive Force $\left(H_{R C}\right)$, and Mean Destructive Field (MDF)}

Figures 3 and 4 show the distributions of $H_{C}$ and $H_{R C}$, and the distribution of the ratio $H_{R C} / H_{C}$ is shown in Figure 5. These values are typical of large pseudo single domain titanomagnetites. According to a theory proposed by Stoner and Wohlfarth (1948), in the limiting case of a random assemblage of identical, noninteracting single domain grains, $H_{R C} / H_{C}=1.09$. As grain size increases through the pseudo single domain range, $H_{R C} / H_{C}$ increases to about 3. For values of $H_{R C} / H_{C}$ greater than 3 , one is looking at predominantly multidomain grains. In the absence of $H_{R C}$ and $H_{C}$ measure- 

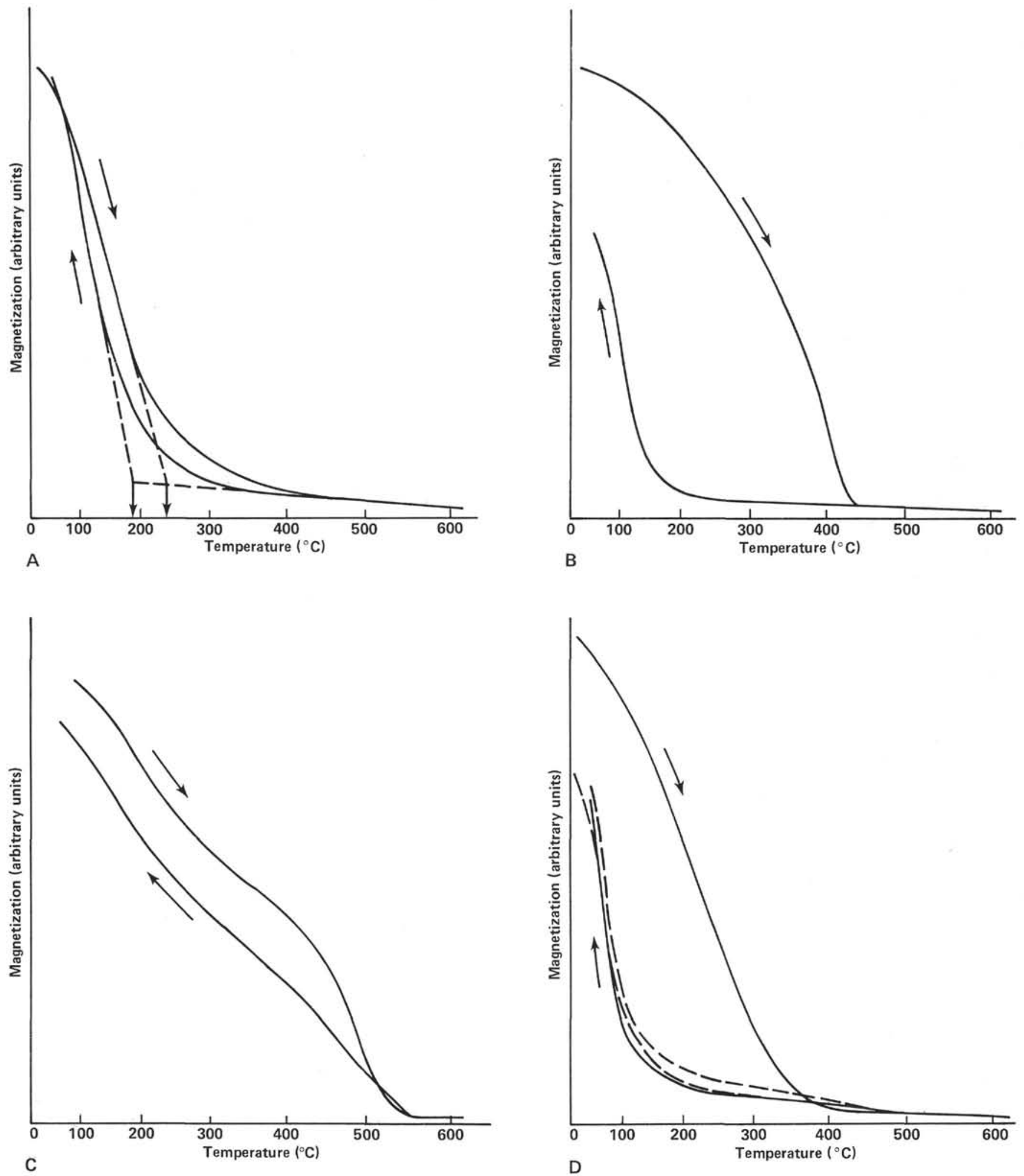

Figure 1. Variation of magnetization with temperature for representative samples. (Heating and cooling curves are indicated by arrows.) (A) Thermomagnetic curve showing reversible behavior (Section 485A-17-1, 108). Broken lines denote the graphical method of Curie temperature determination; (B) curve showing irreversible behavior (Section 482C-10-2, 58); (C) two Curie temperature curves (Section 482B-16-1, 117); (D) irreversible curve showing almost perfect reversibility of second heating and cooling cycle (Section 482D-10-2, 57). 
Table 2. Average magnetic properties of basalts for each hole drilled on Leg 65 .

\begin{tabular}{lrcccccccrr}
\hline Hole & $\begin{array}{c}\mathrm{MDF}(1) \\
(\mathrm{Oe})\end{array}$ & $\begin{array}{c}J_{R S} \\
\text { (gauss) }\end{array}$ & $\begin{array}{c}\mathrm{MDF}(2) \\
\text { (Oe) }\end{array}$ & $\begin{array}{c}J_{S} \\
\text { (gauss) }\end{array}$ & \multicolumn{1}{c}{$J_{R S^{\prime} / J_{S}}$} & $\begin{array}{c}H_{C} \\
(\mathrm{Oe})\end{array}$ & $\begin{array}{c}H_{R C} \\
(\mathrm{Oe})\end{array}$ & \multicolumn{1}{c}{$H_{R C} / H_{C}$} & $\begin{array}{c}\chi \\
\text { (gauss/Oe) }\end{array}$ & $Q$ \\
\hline $482 \mathrm{~B}$ & 53 & 0.409 & 38 & 2.54 & 0.17 & 47 & 70 & 1.55 & 2.38 & 12.2 \\
$482 \mathrm{C}$ & 51 & 0.301 & 31 & 2.64 & 0.12 & 35 & 62 & 1.82 & 2.75 & 3.2 \\
$482 \mathrm{D}$ & 110 & 0.605 & 68 & 2.81 & 0.21 & 79 & 111 & 1.48 & 6.62 & 9.8 \\
$482 \mathrm{~F}$ & 51 & 0.359 & 29 & 2.51 & 0.14 & 38 & 58 & 1.54 & 2.91 & 7.8 \\
483 & 102 & 0.414 & 49 & 2.04 & 0.21 & 51 & 87 & 1.83 & 2.03 & 19.3 \\
$483 \mathrm{~B}$ & 84 & 0.202 & 36 & 1.92 & 0.11 & 31 & 73 & 2.38 & 2.37 & 3.4 \\
$485 \mathrm{~A}$ & 79 & 0.344 & 45 & 2.84 & 0.12 & 42 & 92 & 2.19 & 3.14 & 3.8 \\
\hline
\end{tabular}

Note: $M D F(1)$ is the mean destructive field from NRM demagnetization; $J_{R S}=$ saturation remanence; $M D F(2)$ is mean destructive field from isothermal remanence demagnetization; $J_{S}=$ saturation magnetization: $H_{C}=$ coercive force; $H_{R C}=$ remanent coercive force; $x=$ susceptibility; $Q=$ Koenigsberger ratio based on a magnetic field $H_{0}=0.45$ Oe.

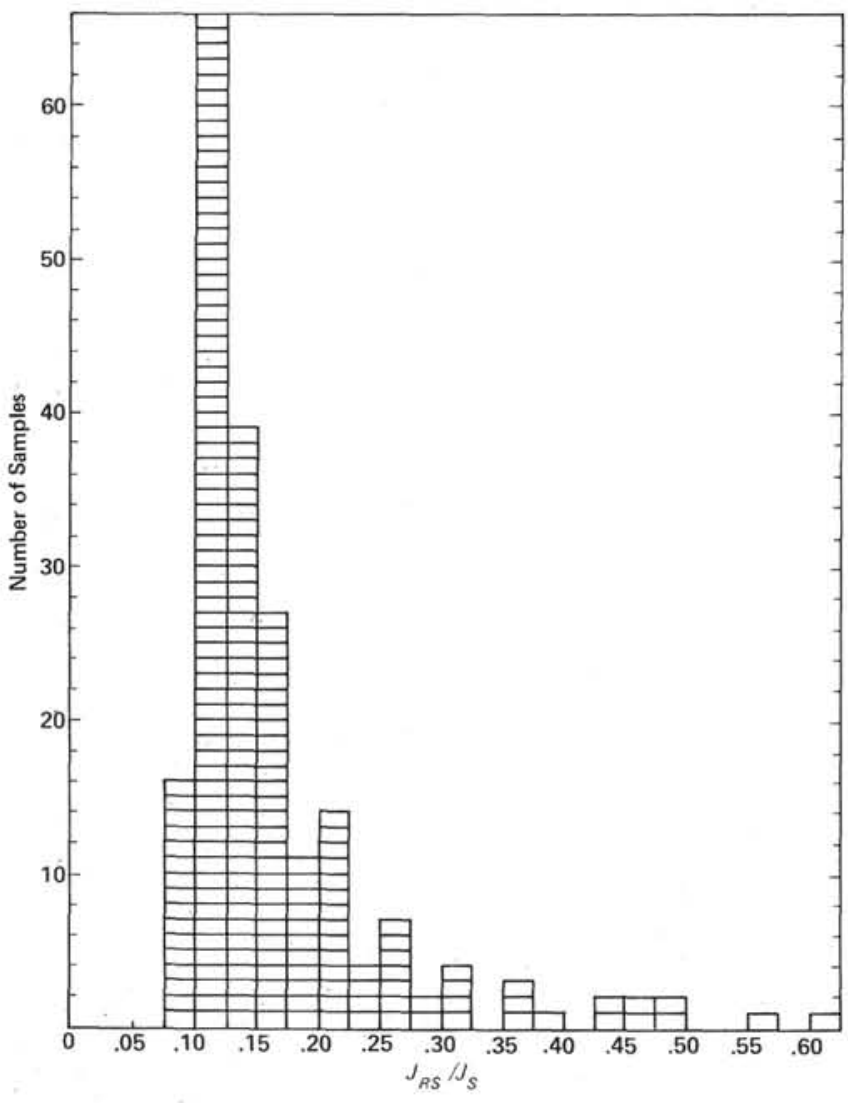

Figure 2. Histogram of the ratio $J_{R S} / J_{S}$ (all sites).

ments, the median destructive field (MDF) has commonly been used to estimate the coercivity distribution. Two MDFs are listed in the tables. MDF(1) is the median destructive field from the NRM demagnetization curve, and $\operatorname{MDF}(2)$ is from the saturation isothermal remanence demagnetization curve. The observation that $\operatorname{MDF}(1)$ is generally greater than $\operatorname{MDF}(2)$ again indicates the presence of pseudo single domain grains on the basis of the Lowrie-Fuller test.

\section{Other Magnetic Measurements}

The paleomagnetic results for the Leg 65 basalts have been presented elsewhere (Day, this volume). For completeness we have shown the distributions of NRM, the Koenigsberger ratio $(Q)$, and stable inclination $\left(I_{0}\right)$ in Figures 6,7 , and 8 .

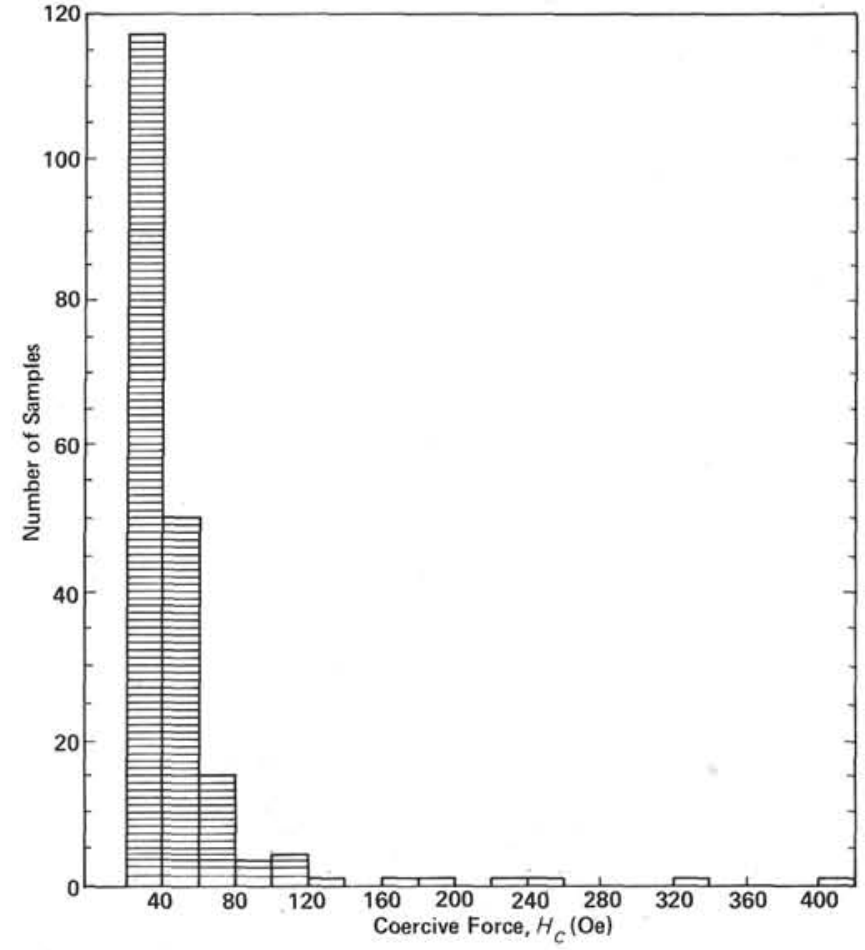

Figure 3. Histogram of coercive force, $H_{C}$ (all sites).

Several samples were selected for thermal demagnetization studies (Day, this volume). Although the temperature dependence of the NRM appears to be valid, the stable inclinations determined from the demagnetization curves are noticeably different from those found in neighboring samples that were AF demagnetized.

\section{DISCUSSION}

The Curie temperature of a completely unaltered oceanic basalt should be about $125^{\circ} \mathrm{C}$ (Peterson et al., 1979). Since the variability of the primary composition (i.e., the presence of minor constituents such as $\mathrm{Mg}, \mathrm{Al}$, and $\mathrm{Cr}$ ) is limited in submarine basalts, we can expect an unaltered oceanic basalt to have a Curie temperature of $125^{\circ} \mathrm{C}$ with a variation of about $\pm 50^{\circ} \mathrm{C}$ from this value. The Curie temperatures obtained from the cooling curves in our thermomagnetic experiments fall within this range. Values obtained from the heating curves, however, are systematically higher. In fact, the difference, $\Delta T_{c}$, between the two Curie temperatures (a 


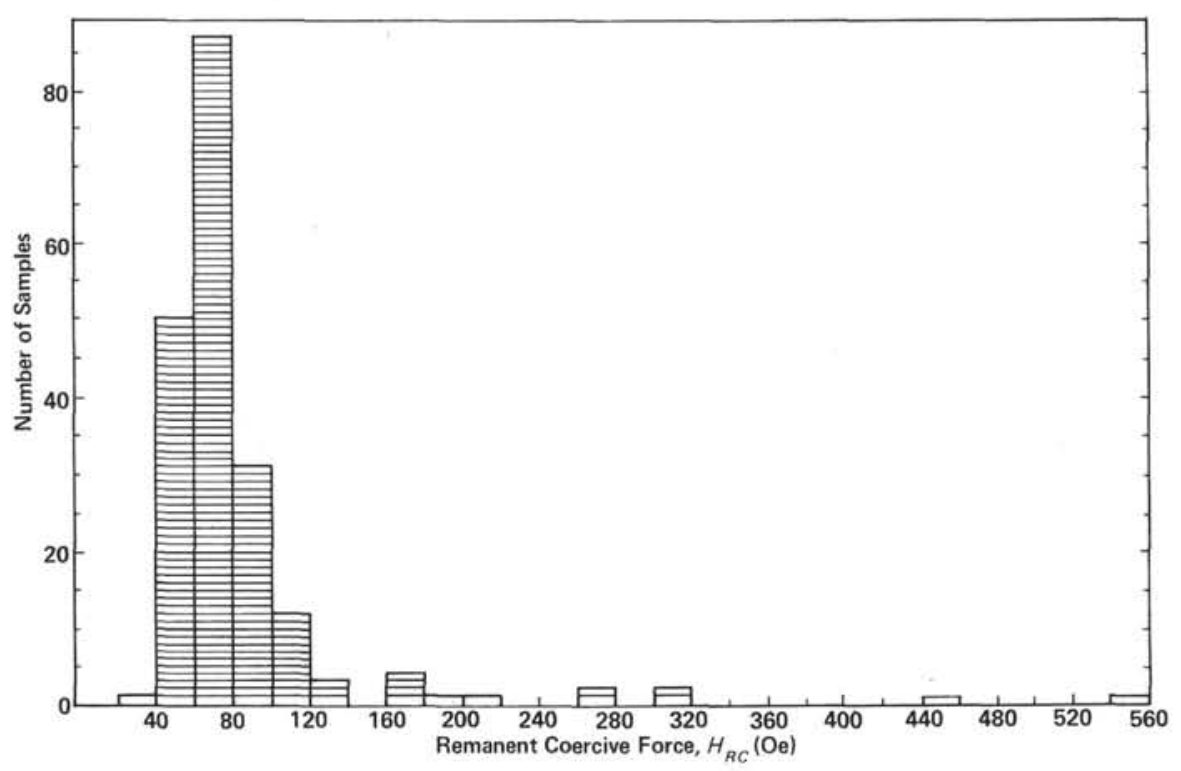

Figure 4. Histogram of remanent coercive force, $H_{R C}$ (all sites).

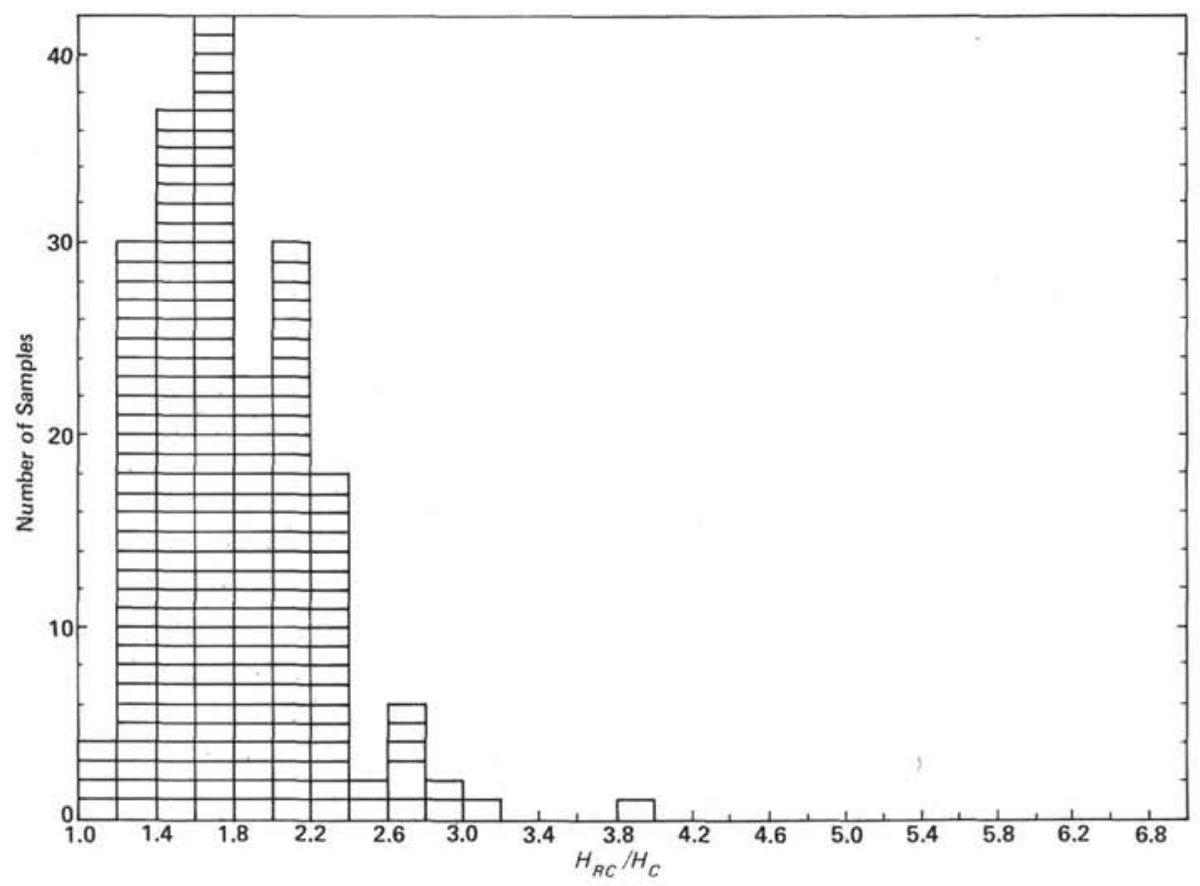

Figure 5. Histogram of the ratio $H_{R C} / H_{C}$ (all sites).

measure of the degree of irreversibility), increases with increasing Curie temperature (Fig. 9). The most likely interpretation for this would be a variable degree of alteration, despite the young age of the Leg 65 basalts.

It is well known that submarine weathering leads to maghemitization (i.e., low-temperature oxidation) of titanomagnetite grains. The metastable alteration product, a cation-deficient spinel phase, has a higher Curie temperature than the original titanomagnetite. Using data obtained from synthetic samples, many authors have used the increase in Curie temperature to determine the degree of oxidation (assuming a uniform orig- inal composition). It has been shown, however, (Johnson and Melson, 1978; Peterson et al., 1979) that the low-temperature oxidation is essentially accomplished by Fe-migration out of the titanomagnetite. Hence the original $\mathrm{Fe} / \mathrm{Ti}$ ratio will not be preserved. Our thermomagnetic results show that a chemical change takes place during the first heating, and that the metastable titanomaghemite is reduced to a stable stoichiometric(?) titanomagnetite because of the low oxygen fugacity. On repeated heatings (Fig. 1D), the behavior is always reversible, but subsequent Curie temperatures are lower than the initial Curie temperature. With the aid of 


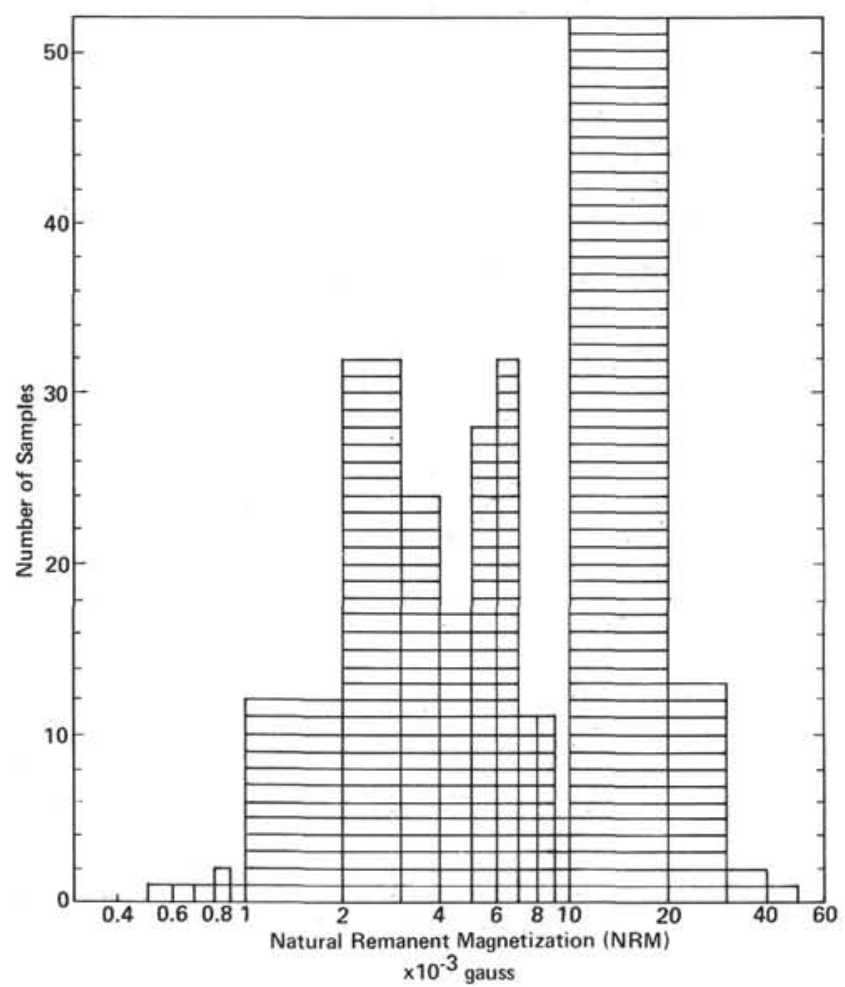

Figure 6. Histogram of NRM intensity (all sites).

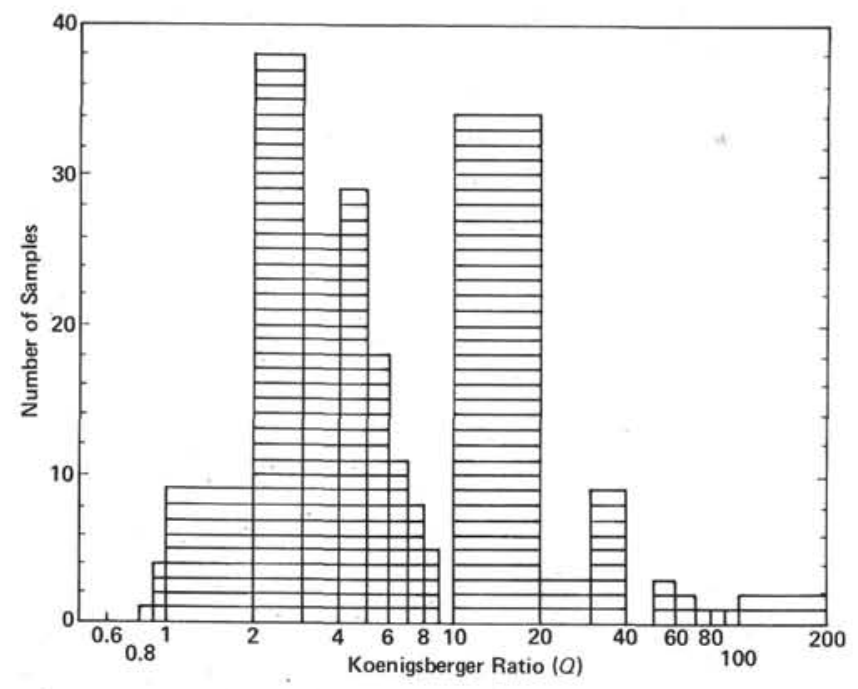

Figure 7. Histogram of Koenigsberger ratio, $Q$ (all sites).

microprobe analyses, it should be possible to relate this difference to the amount of low temperature oxidation that took place. In the present instance, however, the anomalous behavior of the basalts may be due to the fact that the original titanomagnetite composition in the Leg 65 basalts is more variable than in other oceanic basalts. For example, samples from Cores $482 C-11$, 483$22,485 \mathrm{~A}-29$, and $485 \mathrm{~A}-39$ appear to have unusually low initial titanium contents.

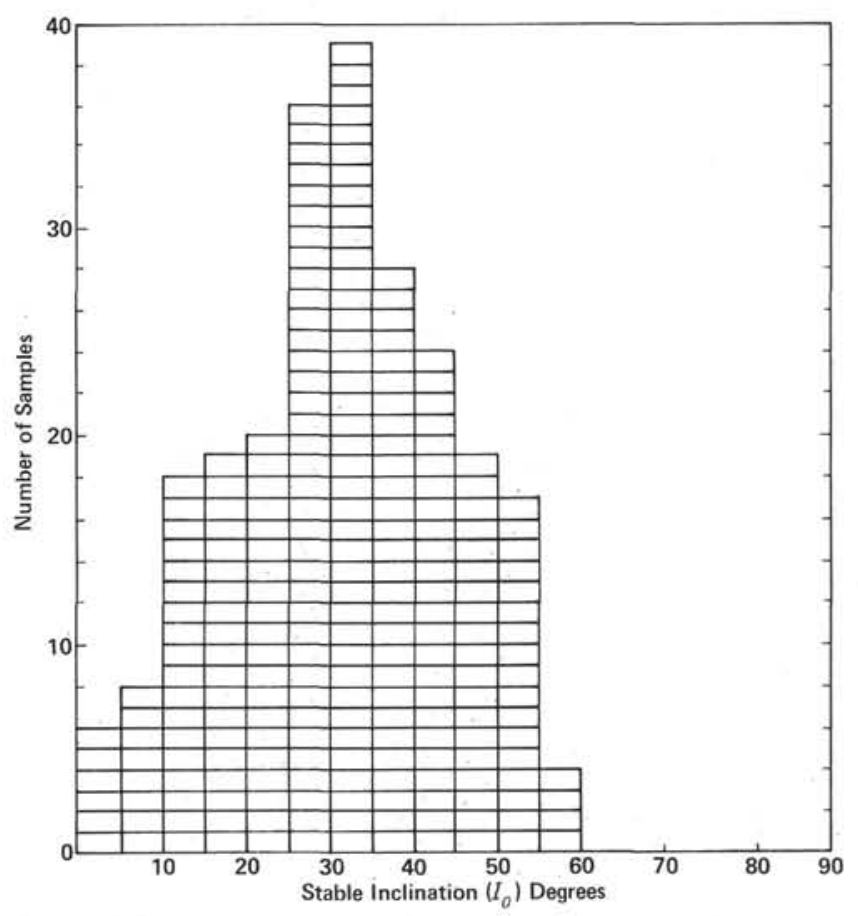

Figure 8. Histogram of stable inclination, $I_{0}$ (all sites).

Alteration is limited in the inner parts of the massive flow units, but for thinner cooling units, the maghemitization can be very high. Moreover, multiphase magnetic mineral assemblages occur in several samples (i.e., Cores 485A-29 through 32), and the titanomagnetites are completely decomposed in Sample 482D-8-1, 106 $\mathrm{cm}$. In view of the young age of the basalts, such extremes may indicate the presence of hydrothermal activity and deuteric alteration.

The magnetic properties of the Leg 65 basalts are remarkably uniform. The only distinct differences reflect the finer grain size of the titanomagnetites in the pillow basalts. The titanomagnetites for the most part are fresh or slightly oxidized with an occasional example of extreme alteration. As can be seen in Figure 10, the magnetic grains fall in the pseudo single domain grain-size category, though grains in the pillow basalts approach single domain size. In comparing the magnetic properties of Leg 65 basalts with those from Leg 49 (Day et al., 1979), it becomes obvious that the Type II basalts found on Leg 49 are missing. While most of the Leg 49 magnetic properties exhibit bimodal distributions, the properties of basalts from Leg 65 each group around a single peak.

\section{ACKNOWLEDGMENTS}

We would like to thank the many people who were responsible for the success of DSDP Leg 65. We are particularly indebted to Barry Davis and Gretchen Green for help with some of the magnetic measurements. This research was partially funded by a grant from the $\mathrm{Na}-$ tional Science Foundation. 


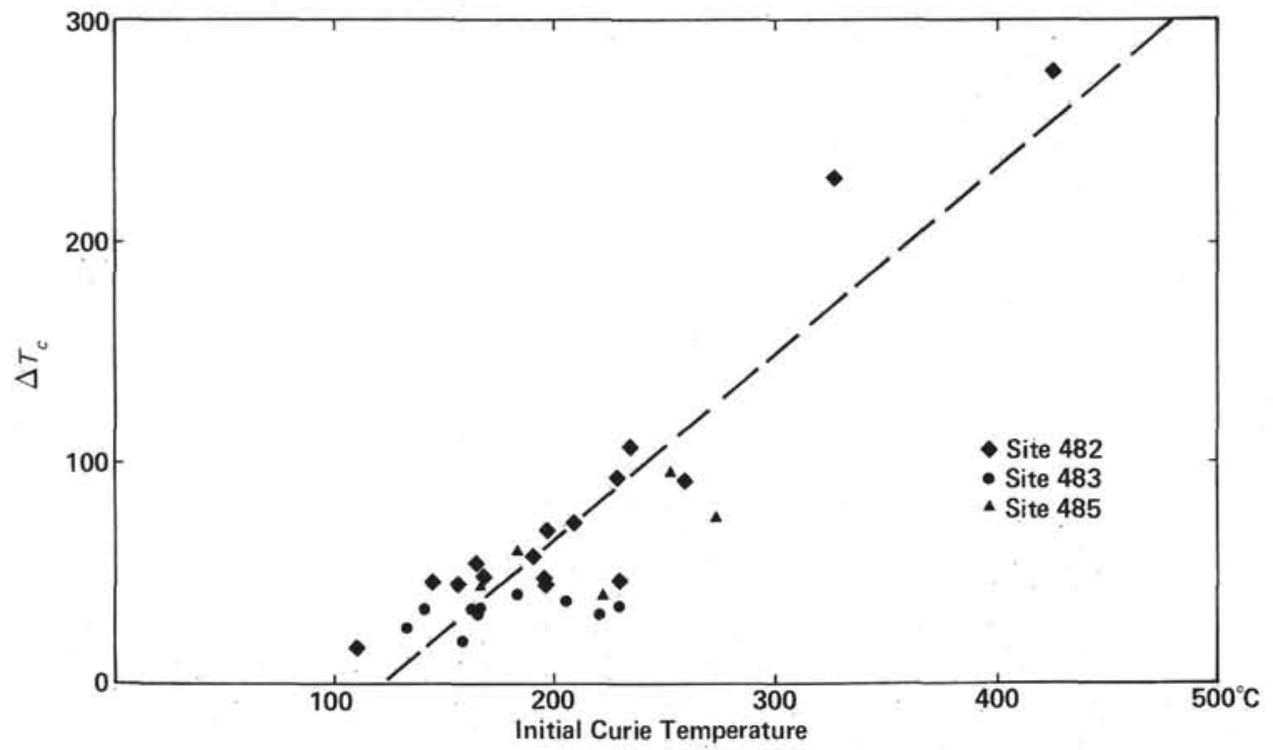

Figure 9. Difference, $\Delta T_{c}$, of Curie temperatures based on heating and cooling curves versus initial Curie temperature based on heating curve. Broken line represents the visual best fit assuming a linear relationship.

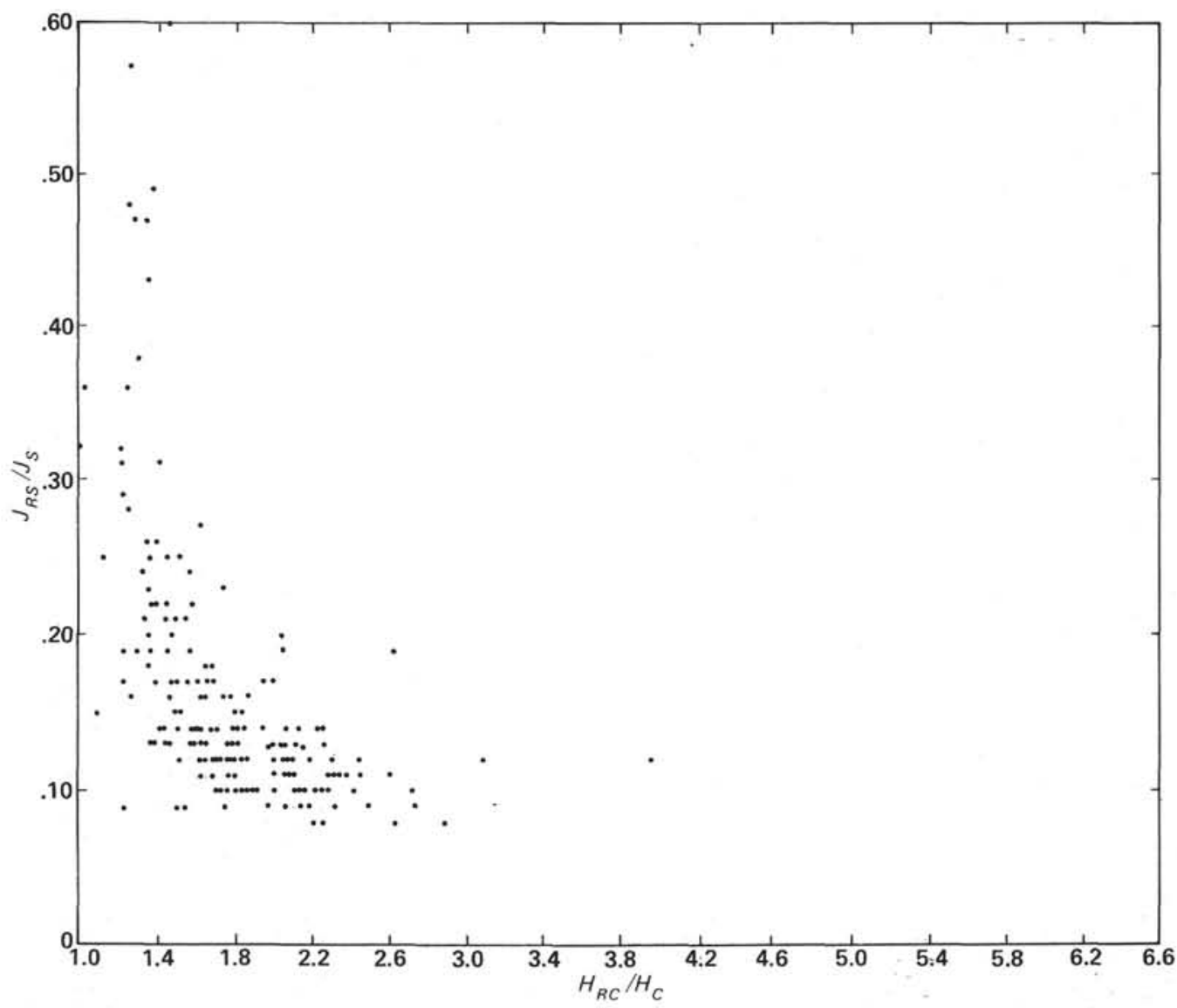

Figure 10. $J_{R S} / J_{S}$ versus $H_{R C} / H_{C}$, (all sites). 


\section{REFERENCES}

Day, R., Halgedahl, S., Steiner, M., et al., 1979. Magnetic properties of basalts from DSDP Leg 49. In Luyendyk, B. P., and Cann, J. R., et al., Init. Repts. DSDP, 49: Washington (U.S. Govt. Printing Office), 781-791.

Grommé, C. S., Wright, T. L., and Peck, D. L., 1969, Magnetic properties of iron-titanium oxide minerals in Alae and Makaopuhi lava lakes, Hawaii. J. Geophys. Res., 74:5277-5293.

Johnson, H. P., and Melson, W. G., 1978. Electron microprobe analysis of some titanomagnetite grains from Hole 395A. In Mel- son, W. G., Rabinowitz, P. D., et al., Init. Repts. DSDP, 45: Washington (U.S. Govt. Printing Office), 575-580.

Kobayashi, K., and Fuller, M., 1967. Vibration magnetometer. In Collinson, D. W., Creer, K. M., and Runcorn, S. K. (Eds.), Methods in Paleomagnetism: New York (Elsevier), pp. 450-456.

Peterson, N., Eisenach, P., and Bleil, U., 1979. Low temperature alteration of the magnetic minerals in ocean floor basalts. $\mathrm{Am}$. Geophys. Union: Maurice Ewing Ser., 2:169.

Stoner, E. C., and Wohlfarth, E. P., 1948. A mechanism of magnetic hysteresis in heterogeneous alloys. Philos. Trans. R. Soc. London, Ser. A, 240:599-642. 